\title{
PERFORMANCE AIDING OF MOTORCYCLES USING HYBRID TECHNOLOGY
}

\author{
John P Kurian ${ }^{1}$, Jithin George ${ }^{2}$, Jibin A V ${ }^{3}$, Muhammad Majas K $\mathbf{M}^{4}$ \\ ${ }^{1}$ UG Student, Dept of. Electrical \& Electronics Engineering, Mar Athanasius College of Engineering, Kerala, India \\ ${ }^{2} U G$ Student, Dept of. Electrical \& Electronics Engineering, Mar Athanasius College of Engineering, Kerala, India \\ ${ }^{3} U G$ Student, Dept of. Electrical \& Electronics Engineering, Mar Athanasius College of Engineering, Kerala, India \\ ${ }^{4} U G$ Student, Dept of. Electrical \& Electronics Engineering, Mar Athanasius College of Engineering, Kerala, India
}

\begin{abstract}
Rising fuel prices is a major issue faced by the vehicle owners today. Electric vehicles has been introduced in the market but they have not been successful due to various problems like low power output, long charging time, unreliability etc. We hope to solve these problems by the application of hybrid technology. We are designing a hybrid conversion kit which can be implemented on factory made motorcycles for improving their efficiency and performance. Designing a hybrid motorcycle and bringing it into the market can be difficult, but designing a conversion kit, which can be fitted on any motorcycle (old or new), has a higher opportunity in the market.

In this kit, we are including a Brushless DC Motor which can be fitted inside the front tyre. We are also designing a user-friendly interface which allows the user to select the modes of operation which are : Engine only, Motor only or both the motor and engine(hybrid). The microcontroller in the kit senses the variables in the system and decides on the mode of running as per the predefined criteria. This kit allows the user to obtain all the characteristics of both the electric motor and the internal-combustion engine. The power output and the efficiency of the vehicle can be considerably increased using this technology.
\end{abstract}

Keywords: Hybrid Technology, Brushless DC hub motor

\section{INTRODUCTION}

The problems faced by the vehicle owners today are rising fuel prices and the resulting increased cost of living. The crude oil price saw a rapid increase in the last decade due to the change in foreign policies and varying economic conditions in various countries. Shifting to sustainable energy sources has become necessary. But as our lives are thoroughly dependent upon the fossil fuels, a drastic change from fossil fuels to sustainable resources(electricity from sustainable resources), may present many difficulties. An example of this is seen in the automobile industry, although electric cars and scooters have been introduced into the market, they have not yet attained their expected popularity due to their various flaws like low power output, long charging time, unreliability etc. These characteristics are certainly attainable using the existing technology, but it is not possible to provide them at a cost that is acceptable to the masses.

With the ever increasing production and demand of fossil fuel-based automobiles, their electric alternatives are not able to compete with them in the market. Therefore hybrid technology paves way for introducing electric drives into the automobile sector and to help create a much more fuel efficient and greener vehicle. In hybrid vehicles an electric motor is used alongside an internal combustion engine for powering the vehicle. Hybrid cars are already manufactured by Porsche and Toyota, but they have not yet been introduced in motorcycles because of their lack of popularity in the western economy. However in the southAsian countries motorcycles play an integral role in the transportation sector. In this project we are designing a hybrid conversion kit which can be used to convert any factory made motorcycle into a hybrid motorcycle. This kit involves a brushless dc motor for powering the motorcycle and a microcontroller for controlling the motor and the engine and enabling them to run together without conflicts. In order to come up with a system in which the user can dictate the controller to run in whichever mode he desires, a user interface is also designed. A product can only succeed in the market if it is able to meet the meet the requirement of the user and maximum effort has gone into designing this kit so that is user acceptable.

\section{BLOCK DIAGRAM}

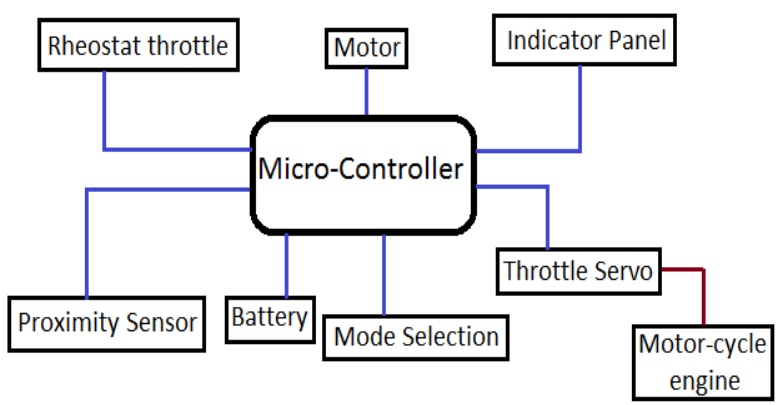


The BLDC motor and the microcontroller can be powered by using $412 \mathrm{~V}$ batteries capable of providing 7Ah.

The mode of operation of the system is determined by the mode selection switches placed in the control panel. The user can select one of the three modes of operation by using two switches. The Rheostat throttle is used for controlling the speed of the vehicle. Proximity sensor is used for determining the speed of the vehicles for providing the appropriate control signals. The throttle servo is used as an actuator for controlling the air intake input and subsequently controlling the internal combustion engine. The indicator panel is a part of the user interface and it consists of LED's displaying the mode of operation of the vehicle

\section{OPERATING MODES}

There are different modes of operation of the vehicle. They are:

1. Mode 1 : Operates on Internal Combustion engine alone

2. Mode 2 : Operates on Electric motor alone

3. Mode 3 : Hybrid Mode : Operates on both the Internal Combustion engine and the Electric motor

\subsection{Mode 1}

When the mode 1 operation is selected by the user, the vehicle relies solely on the power developed by the Internal combustion energy for its operation. The fuel efficiency is lower in such a mode of operation. This mode is provided as a contingency so that the user is not stranded by the side of the road in case the battery aboard has drained out.

\subsection{Mode 2}

In mode 2 operation, the electric motor mounted on the wheels provides the power. The Internal combustion engine is not used in this mode and it can be decoupled from the transmission by engaging the clutch or by shifting into the neutral gear. This is a highly efficient mode of operation and can be used in when the load on the vehicle is low or when cruising at higher velocities.

\subsection{Mode 3 (Hybrid Mode)}

When the mode 3 is chosen by the user, the electric motor is used alongside the internal combustion engine for providing the power. When travelling at lower speeds the vehicle relies on the I.C engine and once a predefined cruising speed (30Kmph) is attained, the machine shifts into the electric mode. If the speed falls below the cruising speed, the I.C engine is again used. This mode makes use of the advantages of both the power sources. The BLDC electric motor has lower starting torque but can run efficiently at higher speeds, on the other hand the I.C engine has higher starting torque but poorer efficiency when compared to the electric motor. Excessive battery power consumption during the starting of the BLDC motor can be avoided by applying this method. Higher fuel efficiency and excellent running characteristics can be obtained by using this mode of operation.

\section{POWERING THE VEHICLE}

The hybrid conversion kit is fitted along with the battery, throttle controller, proximity sensor and BLDC hub motor. They are installed on the motorcycle as shown in the following diagram

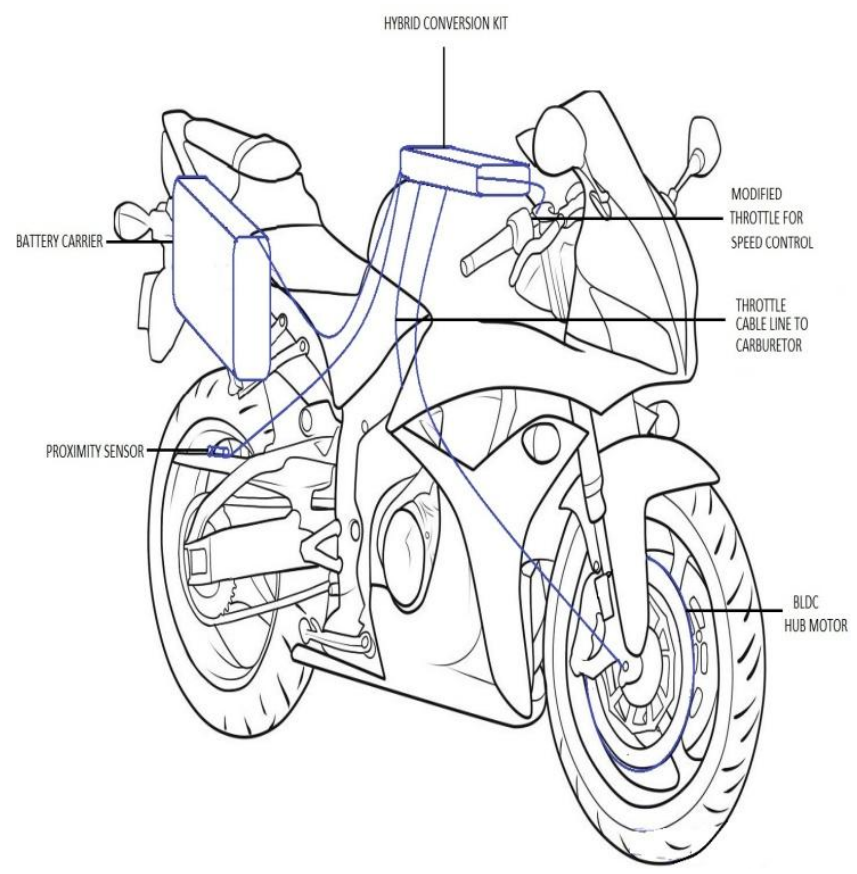

The Hybrid Conversion kit can be mounted on top of the fuel tank. In stock motorcycles, the engine is controlled by a throttle cable attached to the hand twist throttle. But once the vehicle is converted into a hybrid vehicle, we need to control a BLDC hub motor along with the engine, therefore we have to replace the twist throttle with a twist variable resistance pot.

The conversion kit has an Atmega microcontroller for its operation. The microcontroller receives inputs from the throttle pot, the proximity sensor and the mode selection switches. Depending upon the input from the mode selection switches, the mode of operation is set. If it is operating in Mode 1 (engine only), the input of the throttle sensor is used to rotate the throttle servo in the corresponding angle. In Mode 2, the throttle servo input is used to provide the output to the BLDC hub motor. The speed of the motor can be controlled by varying the voltage output to the motor. A PWM pin is used to provide the variable output to the motor.

In Mode 3 operation is selected, a proximity sensor is used to sense the speed of the vehicle. The proximity sensor is mounted on the body of the vehicle near the rear wheel. A metal piece is fitted on the wheel for sensing. In the mode 3 program loop, a counter is added to determine the rpm of the rear wheel. The counter maximum value for a cruising speed of $30 \mathrm{Km} / \mathrm{h}$ is set as 2000 . When the counter crosses the value, the switching between the motor and the engine takes place. 


\section{CONCLUSIONS}

The use of hybrid technology can increase the fuel efficiency of the automobile and provide enhanced performance characteristics. A hybrid conversion kit as demonstrated by this project has a huge market potential considering the rising fuel prices and depleting crude oil reserves.

\section{ACKNOWLEDGEMENTS}

We thank the almighty for bestowing upon us all his blessings for the compilation of this paper. We extend our sincere thanks to Prof.Radhakrishnan K, Head of the Department for providing us with the guidance and facilities for the project and for publishing of this paper. We express our sincere gratitude to Prof, Acy M Kottalil, staff in charge, who coordinated the project, for his cooperation and guidance for preparing and presenting this paper. We also extend our sincere thanks to all other faculty members of Electrical and Electronics Department and our friends for their support and encouragement.

\section{REFERENCES}

[1]. R.P. Joshi,A.PDeshmukh,"Hybrid Electric Vehicles : The Next Generation Automobile Revolution"Electric and Hybrid Vehicles, IEEE Conference 18-20 Dec 2006.

[2]. Ian Vince McLoughlin, I. KomangNarendra, Leong HaiKoh, QuangHuy Nguyen, BharathSeshadri, Wei Zeng,and Chang Yao, "Campus Mobility for the Future: The Electric Bicycle", January 2012

[3]. A. Szumanowski, Warsaw Univ.,'Energy distribution in plug-in hybrid vehicle power trains", International Conference onPower Engineering, Energy and Electrical Drives (POWERENG), 2011 , May 2011

[4]. B.E Kepple,"The triple hybrid vehicle",Universities Power Engineering Conference (AUPEC), 2010 20th Australasian, Dec 2011 